
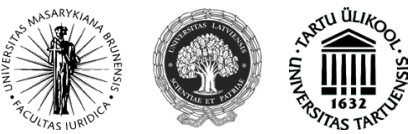

ISSN 1392-6195 (print) ISSN 2029-2058 (online) JURISPRUDENCIJA JURISPRUDENCE 2014, 21(2), p. 531-554.

\title{
THE GOVERNANCE OF MUTUAL RIGHTS AND OBLIGATIONS OF ICANN AND THE REGISTRIES FOR CCTLDS ON THE EXAMPLE OF THE .PL (POLAND), .LT (LITHUANIA) AND OTHER SELECTED DOMAIN NAMES ${ }^{1}$
}

\author{
Mariusz Zelek \\ Department of Civil, Commercial and Insurance Law, \\ Faculty of Law and Administration, \\ Adam Mickiewicz University, \\ Niepodległości al. 53, \\ 61-714 Poznań, Poland \\ Tel.: + 48618294268 \\ E-mail: mariusz.zelek@yahoo.pl
}

Submitted on 16 of March, 2014; accepted on 26 of May, 2014

doi:10.13165/JUR-14-21-2-10

\section{Introduction}

Nowadays the registration of Internet domains is a common phenomenon. The total number of domain names registered on a global scale runs into hundreds of

1 The article was written within the framework of a research project entitled "The Content of the Entitlement of Naukowa i Akademicka Sieć Komputerowa (NASK) to Perform the Function of Registry for the Country Code Top Level Domain for Poland in Light of the Delegation of Subdomains under the Agreement on the Registration of an Internet Domain Name with the .pl Suffix", for the performance of which the author was awarded a research grant by the Dean of the Faculty of Law and Administration at Adam Mickiewicz University in Poznań.

Jurisprudencija/Jurisprudence

(C) Mykolo Romerio universitetas, 2014

(C) Mykolas Romeris University, 2014
ISSN 1392-6195 (print), ISSN 2029-2058 (online) http://www.mruni.eu/lt/mokslo_darbai/jurisprudencija/ http://www.mruni.eu/en/mokslo_darbai/jurisprudencija/ 
millions. As a rule, an Internet domain name is registered under a civil-law agreement made between the registering party (the subscriber) and the entity referred to as the domain name registry.

The entity responsible for the central and global management of Internet domains is an organization called the Internet Corporation of Assigned Names and Numbers (ICANN), headquartered in California, the United States. This entity is involved in the cooperation with Top Level Domain Registries, under which the latter are empowered to manage specific parts of the global system of Internet domain names.

This article is an attempt at establishing the content of the legal relationship between ICANN and the registry for the country code Top Level Domain (ccTLD). The focus of the deliberations is on defining mutual rights and obligations of the parties to the agreements pertaining to the domain name for Poland (.pl) and Lithuania (.lt). To make authoritative statements on the content of the legal relationships created through the said agreements, operating on the assumption of the standardization of all the activities taken by ICANN, the author has studied the content of all available agreements made in writing by ICANN with Registries for other country code Top Level Domains. Such an operation has been indispensable in view of the fact that mutual relationships between ICANN and the Registries for the . $\mathrm{pl}$ and .lt domain names are not based on written agreements, which means that the content of the agreements on the management of the said domain names cannot be subject to analysis.

The subject matter of this article has not been addressed in legal literature yet. The author has found that so far no study has been made into the legal relationship between ICANN and the Registry for ccTLD and that, with absolute certainty, no publication addresses the issue in question in the context of the .pl domain name. The author has no knowledge on the existence of any study pertaining to the lt domain name. The examined problem is sometimes being mentioned only marginally, authors are pointing at the fact itself, rather than analysing the content of mutual rights and obligations going beyond the general assumptions that can be found on ICANN's web page or in the document containing general assumptions of ccTLDs delegation - written by the creator of DNS - Jon Postel (the so-called Request for Comments 1591)2. The review of accessible legal literature leads to a conclusion that the questions discussed in this paper are omitted. Authors discussing legal aspects of domain names and ICANN's activity focus mainly on the subject of Internet Governance ${ }^{3}$, the conflicts between domain names and other distinctive signs

2 Postel, J. Domain Name System Structure and Delegation. Request for Comments. 1591 [interactive]. [accessed on 2014-03-03]. <http://www.ietf.org/rfc/rfc1591.txt >.

3 See, among others: Kulesza, J. International Internet Law. New York, 2012, p. 125-136; see also: Froomkin, A. M. Wrong Turn in Cyberspace. Using ICANN to Route around the APA and the Constitution. Duke Law Journal. 2000, 50: 17-184; Klein, H. ICANN and Internet Governance: 
(especially trademarks) ${ }^{4}$, issues concerning legal protection of a domain name ${ }^{5}$, legal characteristic of a domain name itself $f^{6}$, domain name dispute resolution matters ${ }^{7}$ or consumer protection problems ${ }^{8}$. Publications discussing together several issues from the ones mentioned above are also met in literature ${ }^{9}$. An attempt to find publications describing the content of contractual relation between ICANN and ccTLD Registries, especially those based on a written document of agreement, also ended in failure ${ }^{10}$.

In view of the above stated, the considerations presented in this article are grounded solely on the analysis of source texts, such as written agreements made by ICANN with the Registries for certain ccTLDs, the analysis of the responses supplied by ICANN, the Registries for certain ccTLDs and by other institutions to the questions put by the author, and on the conclusions drawn from investigating the operational practice of Registries for cc Top Level Domains.

Leveraging Technical Coordination to Realize Global Public Policy. The Information Society. 2002, 18: 193-207.

4 See, among others: Lipton, J. Internet Domain Names, Trademarks and Free Speech. Cheltenham-Northampton, 2010; see also: Malisuwan, S.; Xu, J. Conflict of Domain Name and Trademark in Thailand. International Journal of the Computer, the Internet and Management. 2007, 1(15): 63-70; Dinwoodie, G. B. (National) Trademark Law and the (Non-national) Domain Name System. University of Pennsylvania Journal of International Economic Law. 2000, 3(21): 495-521; Parchomovsky, G. On Trademarks, Domain Names, and Internal Auctions. University of Illinois Law Review. 2001, 1: 211-240; Jacobs, G. Internet-Specific Collisions of Trademarks in the Domain-Name System - An Economic Analysis Based on U.S. Law. International Review of Intellectual Property and Competition Law. 2006, 2(37): 156-179; Senftleben, M. The Trademark Tower of Babel - Dilution Concepts in International, US, and EC Trademark Law. International Review of Intellectual Property and Competition Law. 2009, 1(40): 45-77.

5 See, among others: Wang, F. F. Domain Names Management and Legal Protection. International Journal of Information Management. 2006, 26: 116-127.

6 See, among others: Sauliunas, D. Problems of Legal Nature of Internet Domain Names. Jurisprudencija. 2003, 47(39): 29-37.

7 See, among others: Apke, T. M. Legal Strategies in Resolving Domain Name Disputes. Industrial Management \& Data Systems. 2003, 103/5: 332-228.

8 See, among others: Ng, J. The Domain Name Registration System. Liberalization, Consumer Protection and Growth. New York, 2013.

9 See, among others: Komaitis, K. The Current State of Domain Name Regulation. Domain Names as Second-class Citizens in a Mark-dominated World. New York, 2010; see also: Mukherjee, S. Passing off in Internet Domain Names - A Legal Analysis. Journal of Intellectual Property Rights. 2004, 9: 136-147; Bettinger, T. (ed.). Domain Name Law and Practice. An International Handbook. New York, 2005; Bettinger, T. (ed.). Handbuch des Domainrechts. Nationalne Schutzsysteme und international Streitbeilegung. Cologne-Munich, 2008.

10 These findings are surprising, taking into consideration the number of ccTLDs in the cyberspace and a period of over twenty years of their existence. However, it must be highlighted that the author of this paper is aware that the negative effect of the investigation may also be caused by the lack of accessibility to a number of foreign materials. 


\section{Domain Name - Key Information}

The Internet is a global network of interconnected computers capable of communicating between one another. To enable an efficient and seamless communication between the computers, each of them must have its unique identifier in the network at a given moment in time, which operates like a postal address in the physical world. In virtual reality, this identifier has the form of IP (Internet Protocol) address. At a given point in time, the IP is unique for each computer in the network.

The numerical representation of IP is not easy for a human mind, because it is not intuitive, but difficult to memorize. Hence, a mechanism had been invented to represent the numbers in the IP address as letters of alphabet and numerals. The DNS system (Domain Name System) translates the strings of letters, numerals or specific symbols into an IP address, which is used by computers for communication between one another.

An Internet address is the address of a given device in the network, represented as an alpha-numerical code. This address can assume the format of an e-mail address (e.g., john@smith.pl) or a website address (e.g., http://www.smith.lt). An Internet domain name can be, on the other hand, referred to as a constituent element of the Internet address, which has the format of a string of ASCII-based characters separated with a dot “.” or with “@”. This paper proceeds to discuss website addresses and domain names contained in them.

The domain name system is hierarchical in structure. The hierarchy involves Top Level Domains and lower-level domain names (also referred to as subdomain names). The levels in the address are separated with dots and the rightmost characters represent the top level, with lower-level domain names progressing to the left.

Top Level Domain Names - the so-called TLDs - are sometimes referred to as the "suffix of the website address" or the "domain name extension". Top Level Domains are further divided into country code Top Level Domains and generic Top Level Domains. These domain names occupy the top position in the hierarchy of the DNS. The paper discusses the matters concerning ccTLDs.

Country code Top Level Domains - ccTLDs - are two-lettered and denote a specific country or an autonomous geographic area (except for the .eu). Their examples are as follows: .pl for Poland, .ps. for the State of Palestine, .hk for Hong Kong, or .ru for the Russian Federation. The allocation of a domain name to a specific territory does not entail subjective constraints with respect to registering lower-level domain names in a given ccTLD set. In principle, an entity seated or resided in one country may register a subdomain in the set of subdomain names for another country even for the purpose of conducting business or undertaking another activity outside of the territory of this country. 


\section{Administering Internet Domain Names}

The management of Internet domain names has an extensive multi-level structure. Administration is exercised at the following levels:

1) Central - operated by ICANN and IANA,

2) National - operated by the so-called country code Registries and pertaining to ccTLDs,

3) Institutional - operated by specific institutions and pertaining to gTLDs,

4) Individual - operated by the entities, for which the second- and lower-level domain names are being registered.

The central administration of Internet domain names is the responsibility of ICANN, a private sector, non-profit organization, established in $1998^{11}$. This institution was created to take over from the American government the administration of the DNS system and transfer it to the global community with a view to enhancing competition and international participation in the administration process. ICANN operates under the agreement with the United States Department of Commerce, and the first document of relevance was the Memorandum of Understanding Between ICANN and U.S. Department of Commerce of 25 November 1998. The agreement currently in force is the Affirmation of Commitments of 30 September 2009. Initially, the DNS was managed by an organization called IANA ${ }^{12}$. IANA evolved in the 1970s from an informal association called IETF ${ }^{13}$ with the purpose of launching and administering the DNS system. Currently, the key goal of IANA is to consult with ICANN the Internet standards developed by IETF. From a formal perspective, IANA is still an ICANN department.

The functioning of Top Level Domains (country code and generic) is basically coordinated by ICANN, although some country code Registries are not "accredited" by ICANN, but directly by the United States Department of Commerce ${ }^{14}$. ICANN

11 Internet Corporation for Assigned Names and Numbers.

12 Internet Assigned Numbers Authority.

13 Internet Engineering Task Force is an open international community, aim of which is to promote and improve Internet standards; currently, it operates within the structure of the Internet Society; IETF issues the so called Request for Comments (RFC) - a memorandum describing the methods, behaviour, findings of studies and the innovations which set Internet standards.

14 Although most, though not all the Registries for ccTLD enter into agreements with ICANN on the domain name administration; some Registries enter into relationships with the United States Department of Commerce and perform under such an agreement the functions of ccTLD Registry in a given country (an example is NeuStar Inc. - the Registry for the ".us" domain name or VeriSign - the Registry for, among others, ".tv" domain name). It should be highlighted that, in the scope in question, the criterion which governs the allocation of competency between ICANN and the United States Department of Commerce is not known and does not arise from any available documents. 
enters into agreements with other entities ${ }^{15}$, entrusting them with the administration of specific domain names (to some extent) and, thus, making them the Registries (the Registries for subdomain names) within these domain names. In particular, such entities are given the power to establish the principles for registering and operating subdomain names under a given domain name. Pursuant to the agreement with ICANN, the function of Registry for the .pl ccTLD is performed by a research institute - the Research and Academic Computer Network, referred to as NASK (Naukowa i Akademicka Sieć Komputerowa), with its registered office in Warsaw. The function of the Registry for the .lt ccTLD is performed by the Kaunas University of Technology. Second- or lower-level domains are managed individually by the entities, for which they were registered pursuant to the agreements concluded with higher-level Registries.

\section{The Governance of Mutual Rights and Obligations of ICANN and the Registries for Top Level Domains}

Mutual rights and obligations of ICANN and the gTLD Registry are defined each and every time by an agreement made individually by and between these organizations ${ }^{16}$. Under such agreements, ICANN designates, on the basis of exclusivity, an entity to perform the functions of the Registry, delegating to this entity the competence to establish appropriate procedures regarding, inter alia, subdomain name registration, whereas the said procedures must conform to specific requirements defined each and every time in the very content of the agreement or in appendices attached thereto. It should be also noted that the said agreements may be also amended or renewed, which makes their content much better matched to reality than their original versions.

Leaving aside an extremely controversial issue of ICANN's power to designate a given entity as the Registry for a given domain name ${ }^{17}$, it seems that the practice of making written agreements on the issue in question is proper. In the absence of universally applicable regulations governing the rights and obligations of the parties to such an agreement, defining the said rights and obligations in detail in the contract is the key to ensuring the conduct of legal transactions. What is more, as ICANN

15 These entities may constitute organizational units of private or public sector as well as educational institutions; for example, the Registry for the .biz domain name is NeuStar Inc., an enterprise; for the af domain name - the Ministry of Communication and Information Technology in Afghanistan, and for the .cy domain name - the University of Cyprus.

16 The list and the content of such agreements can be found at: <http://www.icann.org/en/about/ agreements/registries $>$. [accessed on 2014-03-03].

17 To learn more, see, among others: Weinberg, J. ICANN and the Problem of Legitimacy. Duke Law Journal. 2000, 50: 187-260; see also: Liu, J. P. Legitimacy and Authority in Internet Coordination: A Domain Name Case Study. Indiana Law Journal. 1999, 74: 587-626. 
is assumed to operate for the benefit of the global Internet community, then the publication of the entire content of the agreements concluded with the Registries for gTLDs on the website of ICANN should be viewed as a positive thing.

Indeed, the ICANN website features the entire content of the agreements made with the Registries for gTLDs, yet even the fragments of such agreements with the Registries for ccTLDs Registries are nowhere to be found. Instead, there are letters confirming the current situation, namely the performance of the function of Registries for given domain names by designated entities, without defining in detail the rights and obligations of these entities towards ICANN and vice versa ${ }^{18}$. The correspondence refers to only some of ccTLDs domain names operating in the cyberspace. The said documentation can be divided into two categories:

- the letters exchanged between such entities (referred to as "Exchange of Letters") - such letters prevail,

- the documents giving an overview of the scope of mutual responsibilities of the entities towards one another (referred to as "Accountability Framework").

Attention should be given to the fact that there are no binding standards or international agreements describing both the procedure for selecting the entity performing the function of the Registry of ccTLD and the scope of competencies assigned to this entity. Generally speaking, in view of the above stated, ICANN enjoys absolute freedom in this respect. As regards few ccTLDs domain names, standard regulations are put in place, which govern the procedure for establishing an entity performing the function of Registry, yet these are internal (country code or European) regulations, which cannot bind ICANN in any respect. An example of such a regulation is Regulation No. 733/2002 of the European Parliament and of the European Council of 22 April 2002 on the implementation of the ".eu"19 Top Level Domain. The objective of this legal act, as defined explicitly in section 11 of the Preamble and Article 1, is the establishment of the conditions of the implementation of the ".eu" ccTLD, in particular the principles for designating the entity performing the function of the Registry as well as establishing the general policy framework, under which the Registry will operate. The regulation includes, among others, a set of norms pertaining to the registry manager, and, in particular, their responsibilities; what is more, it stipulates the procedure for establishing the principles of public order, governing the implementation and operation of the ".eu" ccTLD, and lays down subdomain name registration rules.

The only ccTLDs, agreements of which were made publicly available on the ICANN website, are the following domains: .au (Australia), .eu (European Union),

18 The list and the content of such letters can be found at: <http://www.icann.org/en/about/ agreements/cctlds $>$. [accessed on 2014-03-03]. 
.jp. (Japan), .ke (Republic of Kenya), .ky (Cayman Islands), .pw (Republic of Palau), .sd (Sudan), .tw (Taiwan), .uz (Uzbekistan), .ps (Palestine), .ng (Nigeria), .md (Moldavia), .af (Afghanistan), .bi (Burundi), .la (Laos), .mw (Malawi) ${ }^{20}$. This fact leads to two alternative conclusions regarding the remaining (over 250) ccTLDs either a written agreement on the delegation of a given domain name was not made public for certain reasons, or such an agreement was not concluded for some reasons.

\subsection{The Agreement between ICANN and NASK}

Since 1990, the function of the Registry for the pl domain name has been continuously performed by NASK (Naukowa i Akademicka Sieć Komputerowa ${ }^{21}$. It should be noted at this point that the sole documents addressing the delegation of the .pl ccTLD, which can be found on the ICANN website, are the letters by both the parties, dated 18 August and 3 September 2008, confirming that NASK holds the status of the Registry for the domain name ${ }^{22}$. No documentation addressing this issue (or no mention of the existence of such documentation) can be found on relevant NASK websites ${ }^{23}$. The analysis of the content of such an agreement would enable a clear definition of the essence and the scope of authority assigned to NASK operating in the capacity of the .pl Registry, which is a matter of prime importance in determining the scope of competency delegated by NASK to the registering party, namely to the other party to an agreement on the registration of a subdomain name with the .pl suffix (in keeping with the nemo plus iuris ad alium transferre potest quam ipse habet principle). As regards the .pl, a subdomain name is registered under a civil-law agreement, under which, putting things simply, the Registry enables the registering party to indicate a website, which is to be displayed after the Internet user types in a specific string of various-level domain names, which combine altogether into an Internet address ${ }^{24}$.

The source of the power of NASK to perform the functions of the .pl Registry is undoubtedly the agreement with ICANN. Since both the entities accept and publicly

20 These agreements are available at: <http://www.icann.org/en/about/agreements/cctlds $>$. [accessed on 2014-03-03].

21 The number of subdomains with the pl suffix exceeds two and a half million, source: $<\mathrm{http}: / /$ www.dns.pl/english/zonestats.html>. [accessed on 2014-03-03]. In terms of the number of registered subdomains, the .pl ccTLD is ranked 6th among country code domains assigned to EU countries, source: <http://www.dns.pl/english/registrar/NASK_Q3_2013_REPORT_ EN.pdf $>$. [accessed on 2014-03-03].

22 These letters can be found at: <http://www.icann.org/en/about/agreements/cctlds $>$. [accessed on 2014-03-03].

$23<$ <ww.nask.pl>; <www.dns.pl>. [accessed on 2014-03-03].

24 From the point of view of the registering party, the set of entitlements arising from the conclusion of the agreement on the registration of an Internet domain can be described as the right arising from the registration of the Internet domain. 
confirm the existence of mutual rights and obligations related to the performance of the function of the Registry for pl. by NASK, it means that there is an understanding between them on this issue, which implies that the relationship between the entities is recognized as contractual. The study that has been conducted shows that the content of this agreement has not been specified. It is most likely that such an agreement has never been concluded in writing, no such document is owned by either NASK or ICANN or by other institutions, which participated in the past or have been participating in coordinating the world system of Internet domains ${ }^{25}$. On top of the above stated, as the data derived from WHOIS database operated by IANA ${ }^{26}$ suggest, initially the delegation of the .pl ccTLD to NASK took place in 1990, which means that ICANN could not delegate the domain name as it was established in 1998. Neither of the above mentioned entities is in the possession of the initial written agreement; it may be, therefore, inferred that already the delegation of the .pl domain name in 1990 was not made in writing.

\subsection{The Agreement between ICANN and Kaunas University of Technology}

Since 1992, the function of the Registry for the .lt ccTLD has been performed without any interruption by the Kaunas Technical University ${ }^{27}$. As has been pointed out above with respect to the delegation of the right to manage the pl domain name to NASK, the ICANN website features some documents confirming the existence of mutual rights and obligations between these entities, yet there are no analogous documents or information concerning the relationship between ICANN and Kaunas University of Technology, the Registry for the .lt. There is no mention of the existence of such documents on the website of the Registry for this domain name ${ }^{28}$. The study has led to obtaining an information from Tomas Mackus - the person indicated in the WHOIS database as being in charge - on behalf of Kaunas University of Technology - of technical issues related to the functioning of the .lt domain name - according to which the Registry for .lt ccTLD is not in the possession of an agreement concluded directly with ICANN, yet it pays ICANN fees for the performance of this function ${ }^{29}$.

25 The information on the absence of such documents was obtained via e-mail from NASK, ICANN, IANA and the University of Southern California in Los Angeles.

26 WHOIS database enables the identification of the entity, on behalf of which a given domain name was delegated, and other issues pertaining to the said delegation, the database is available at: <http://www.iana.org/whois $>$. [accessed on 2014-03-03].

27 The number of subdomain names with the .lt suffix is over 163000 , source: <http://www. domreg.lt/publi c?pg=CFF17D $>$. [accessed on 2014-03-03].

28 <www.domreg.lt>. [accessed on 2014-03-03].

29 The information comes from an e-mail received from Tomas Mackus in reply to the author's questions. 
The behaviour of the parties towards one another, namely, on the one hand, ICANN's failing to call into question of the entitlement of Kaunas University of Technology to perform the function of .It Registry, and the receipt of the fee payments, and, on the other hand, Kaunas University of Technology's payment of the fees to ICANN give rise to a conclusion that, at least per facta concludentia, these entities have entered into contractual relationship, which serves as the actual basis for the cooperation. Hence, mutual rights and obligations of these entities towards one another do not arise from the agreement.

As was the case with the contractual relationship between NASK and ICANN, here also the lack of a written agreement makes a precise definition of the scope of competence assigned to the .lt. Registry highly problematic. Like in the case of the .pl ccTLD, the subdomain names within .lt ccTLD are registered under civillaw agreements $\mathrm{s}^{30}$; hence, also in this particular case, the scope of rights enjoyed by the Registry influences the scope of rights delegated to registering party under the agreement.

\subsection{The Powers of NASK and Kaunas University of Technology in the Management of country code Top Level Domain}

There are 250 country-code Top Level Domains operating in the cyberspace today. An entity in the capacity of Registry is assigned to each domain name. From the technical point of view, the same rules apply to the management of individual ccTLDs. Assuming the standardization of the operations of ICANN, which boils down to delegating to ccTLD Registries similar rights and imposing similar obligations, a certain picture of the content of the legal relationship between ICANN and NASK or Kaunas University of Technology may be given by the analysis of the content of available written agreements concluded between ICANN and other entities performing a similar function with regard to other country code domain names. Such an operation involves a considerable error risk, because individual contractual provisions may be characteristic only to a given contract and may, for example, be the result of negotiations. It appears, however, that generally speaking, also due to technical reasons, the cooperation between the said categories of entities will be governed by similar principles and, in consequence, the legal relationships between them shall have a similar content.

The above-mentioned assumption necessitates investigating the content of available written agreements on establishing a given entity as ccTLD Registry with a view to determining the extent to which they are similar toward one another. It should be stressed at this point that only a relatively high degree of similarity of the

30 See: Procedural Regulation for the .lt Top Level Domain, Section VI [interactive]. [accessed on 2014-03-03]. <http://www.domreg.lt/static/doc/public/procedural_regulation-en.pdf>. 
content of agreements may provide the grounds for drawing conclusions on the content of the agreements regarding other ccTLDs which have not been made in writing.

\subsubsection{The Content of Agreements between ICANN and Selected ccTLDs Registries}

As has been already pointed out, the ICANN website features the documents authorizing specific entities to perform the function of the Registry for a given ccTLD, yet it applies to a relatively small number of domain names compared with the general number of ccTLDs currently in operation. Based on the analysis of the content of available documentation, two groups can be distinguished:

1) Sponsorship Agreements,

2) Memoranda of Understanding.

In principle, both the above mentioned groups exhibit a marked similarity towards one another, whereas Sponsorship Agreements govern mutual rights and obligations of the parties in a more detailed manner. Within a given group, a much more pronounced similarity, or almost uniformity of content, can be observed ${ }^{31}$. In view of the above stated, discussing the wording of the groups of contracts seems to be sufficient, as referring to each and every agreement in the group in isolation would be tantamount to repeating the observations that have been already made.

\subsubsection{Sponsorship Agreements}

The group of Sponsorship Agreements includes ICANN agreements on .uz, .$s d$, .ke, .ky, .pw, .tw, .jp, .au and .eu ${ }^{32}$ domain names, made available on ICANN website. The purpose of the agreements stated in their wording is to reflect each and every time the legal relationship between the parties in a formal written contract. It should be emphasized, to begin with, that all the agreements attach importance to the involvement of the Governmental Authority, representing the territory to which a given ccTLD refers to, in exercising the management of the domain name. This

31 It should be noted that the provisions of the agreement on the eu ccTLD contain certain discrepancies compared with the agreements pertaining to the remaining Top Level Domains, assigned to the group of Sponsorship Agreements. The content of the agreement concerning the .ng ccTLD is characterized by certain discrepancies with regard to the remaining Top Level Domains, allocated to the group of Memoranda of Understanding.

32 It should be noted that the agreement pertaining to the eu domain name, contrary to other contracts assigned to the group under analysis, is not entitled as Sponsorship Agreement, but as an agreement with the Registry for the .eu ccTLD (.eu ccTLD Registry Agreement). The comparison of the content of these agreements has led to a conclusion that they bear considerable similarities to one another, which is why the eu ccTLD agreement is assigned to the group of Sponsorship Agreements. 
involvement is demonstrated, inter alia, by the fact that ICANN designates as the Registry for the domain name the entity, which had been previously approved by the Governmental Authorities, and that the Registry must file a termination notice not only to ICANN, but also to the Governmental Authority body.

The texts of the agreements start with recitals, addressing both the details and the historical background underlying those agreements. The second part contains the definitions of some of the terms that have been used in the contracts. Another relatively large part of the agreement is focused on the obligations of ICANN and the Sponsorship Organization (the Registry for the domain name), followed by the issue of conformity to the standards developed continuously by ICANN, and to DNS operational policy, the possible grounds for the termination of the contractual relationship, accompanied by several other issues of minor importance from the point of view of the subject matter in question. The agreements also include arbitration, salvation and jurisdiction clauses as well as merger and pactum de forma provisions.

ICANN obligations stipulated in the agreements include:

a) Recognition of the other party as the Registry for a given domain name during the term of the agreement ${ }^{33}$,

b) Maintenance of a stable, secure and reliable Authoritative-Root database containing the information on ccTLDs operating in the DNS system and the entities administering their registries,

c) Designation of administrative and technical contact persons for reference purposes,

d) Updating of the name server information concerning the links between IP addresses and domain name addresses related to the subdomain names registered under a given ccTLD,

e) Updating the database for the registry contact information,

f) Publication of the information on the delegated domain name in the WHOIS database,

g) Taking measures aimed at coordinating the Top Level Domain system to ensure that it is operated in a stable and secure manner,

h) Maintenance of the records related to the delegation of a given ccTLD,

i) Notification of any changes made to ICANN's contact information.

As a point of departure for discussing the obligations of ICANN towards the Sponsorship Organization, it should be observed that they are by large technical and organizational in nature. These obligations are detailed both in the agreement and in

33 Although no such obligation has been stated expressis verbis in the agreement, yet it does contain a representation of this party, stating that it recognizes the other party as the Registry for a given ccTLD. It becomes evident that such a provision may imply such an obligation, all the more that this statement has been put in the section entitled "Obligations of ICANN" (argumentum a rubrica). 
the attachments thereto. When looking at the registration of a specific subdomain name within a given ccTLD space, what comes to the fore in respect of ICANN obligations is the recognition of the other party as Registry for a given domain name throughout the term of this agreement. This obligation has not been elaborated on in the agreement, yet, undoubtedly, the issue in question is granting the other party an exclusive right to perform the function of the Registry for a given ccTLD. There is no mention of the scope of competence arising from the performance of the said function, in particular, there is no expressis verbis recognition that this entity would enjoy any power with regard to the registration of subdomain names or to the establishment of registration policies (including financial contributions or any registration constraints).

Business practice shows that the core of operations of the Registries for ccTLDs is the registration and maintenance of Internet domain names. This activity can be subsumed as managing a certain part of the DNS system, administering the DNS system within a given geographic area, or, to be more precise, within a given fragment of the cyberspace. The right to perform the function of the Registry gives rise to a number of more specific powers, such as the right to confer certain new rights on domain name subscribers under the Internet domain name registration agreement. An effective acquisition of this right by the Registry means that the registering party (the domain name subscriber) may also effectively acquire rights under the act in law performed with the Registry. It leads to a conclusion that acquiring, pursuant to the agreements under analysis, the right to perform the function of the Registry for ccTLD by specific entities provides the initial grounds for the subscriber to acquire rights under the registration of an Internet domain name.

The obligations of Sponsorship Organizations stipulated in the agreements under analysis are as follows:

a) Ensuring that name servers for the delegated ccTLD are operated and maintained in a stable and secure manner,

b) Granting ICANN continuous access to the so-called zone file, containing, inter alia, the lists of connotations between IP addresses and domain names as well as up-to-date data on the registration of subdomain names within a delegated domain name (such obligations have not been provided for in the agreement on the eu domain name),

c) Ensuring the safety and integrity of the Registry database, in particular by the establishment of database backup by a third party,

d) Ensuring the accuracy and completeness of the Registry contact information,

e) Conformity to ICANN policy on the interoperability of the delegated ccTLD with other elements of the DNS system and the Internet,

f) Making periodic financial contributions to ICANN to meet its operating expenses. 
It should be noted that in this case also the obligations of the Registry are technical and organizational in nature; they are elaborated on in both the wording of the agreements and in attachments thereto. The obligation to make financial contributions to ICANN is significantly different in nature, as it constitutes de facto a contractual remuneration payable to ICANN by the Registry of a given ccTLD. Pursuant to section 4.6 in the agreements (section 4.5. in the agreement on the .eu domain name), the amount of financial contribution is determined in accordance with the funding requirements of ICANN and agreed on by the parties in a manner described in the attachment F. It can be argued based on the attachment $\mathrm{F}$ to the agreements under analysis that the financial contribution is the sum of two parts: fixed contribution and variable contribution. Fixed contribution is established by the ICANN Board of Directors and cannot exceed the maximum amount defined in the item 4 of the said attachment. The variable part is calculated on terms established also by the ICANN Board of Directors and depends, inter alia, on the number of subdomain names under registered and maintained under a given ccTLD in a given year. The attachment under discussion sets a cap on the annual contribution to ICANN, whereas the maximum amount of the said financial contribution increases per annum by $15 \%$ and, in some cases, by more percentage points ${ }^{34}$. The contribution is payable to ICANN on a one-off basis or in instalments, and a delay in the payment entitles ICANN to charge contractual interest in the amount of $1 \%$ per month (12\% on an annual basis) unless the law of California provides for a lower amount of maximum interest.

It should be also mentioned that the agreement grants the Registry for a given ccTLD a license for the use of ICANN name and logo to state that it is recognized as a Sponsorship Organization for a given ccTLD. This right is time-limited and valid throughout the term of the agreement; it is royalty-free, worldwide and nonexclusive. The license cannot be transferred and the right to use ICANN logo and name cannot be sublicensed (prohibition against sublicensing).

The issue of mutual accountability for non-performance or improper performance of obligations under the agreement is governed in a relatively unusual way. The agreement contains a clause which states that a breach of the agreement does not give rise to any monetary liability by the party in breach to the other party. Pursuant to the agreement, even the failure to make the agreed financial contribution to ICANN does not give rise to claim any monetary benefits from the Sponsorship Agreement towards the said financial contribution, yet it does constitute a material breach of the agreement. Prima facie the no monetary liability for any breach of the agreement clause not only does not correspond, but even contravenes the

34 To give an idea of the range of the amounts, one should indicate that the maximum annual revenue of ICANN indicated in the attachment F to .ky and .pw ccTLD and agreements, which were concluded in 2003, is at five and a half million dollars. 
provisions giving rise to charge interest by ICANN on contribution payments made in an untimely manner. It seems that the intention behind the said provisions was to influence the legal relationship in such a way, so that neither party could claim compulsory monetary benefits from the other party. The parties have agreed to make any monetary liability arising from the agreement unenforceable and, thus, to make the said obligations natural, ineffective (obligationes naturales). Simultaneously, the discharge of the monetary liability by the debtor by way of the performance of the contractual obligation shall not give rise to claim back the paid amount, as monetary liability shall be undue, and no unjust enrichment will occur on the part of the creditor. The interest referred to the above stated serves as a sanction for failing to meet the payment obligation in a timely manner. In light of the Registry's liability to make the contribution to ICANN, the non-payment of interest, as is the case with the non-payment of the principal, shall constitute a material breach of the agreement, giving rise to terminate the agreement by ICANN (see below).

The agreement pays a lot of attention to the issue of the termination of the contractual relationship between the parties and the consequences that ensue. A Sponsorship Organization may terminate an agreement at any time upon a six months written notice, by submitting a written statement to ICANN and to a relevant body of the Governmental Authority. ICANN may, on the other hand, terminate the agreement only under strictly defined circumstances, namely when:

a) Sponsorship Organization fails to cure "any material breach of the agreement" within 21 days of receipt of a written notice from ICANN on the occurrence of the circumstances constituting such a breach, or within a reasonably longer period of time as may be necessary to cure the said breach with all due diligence (period of notice - 30 days),

b) The Registry Operator's action or failure to act has been recognised by the arbitration court as being in violation of the agreement and, simultaneously, the Registry continues to act or fails to act after a period of time stated in the arbitration decision has lapsed, and, if no such period has been stated upon the lapse of 21 days of the issue of the arbitration decision (period of notice - 30 days),

c) Sponsorship Organization acts or continues to act in a manner recognized by ICANN as endangering the operational stability of the DNS system or the Internet after it has received a seven day notice from ICANN stating that such a threat has been recognized (period of notice - 30 days),

d) ICANN shall be notified by a relevant body of the Governmental Authority that the Registry is in violation of the provisions or agreements concluded between this body and the Registry, or that the term for which the Governmental Authority designated the Registry has expired (termination with immediate effect, yet prior to that, ICANN is obliged to give notice of its intention to terminate the agreement to the Registry), 
e) Sponsorship Organization has been declared bankrupt or has become insolvent (termination with immediate effect).

What is more, it has been specified in the agreement on the eu domain name that it shall be automatically terminated at the end of the term of the agreement between the Registry and the European Commission, however, no later than upon the lapse of 10 years after the date of the agreement between ICANN and the Registry, unless the parties agree otherwise.

The consequence of the termination of the legal relationship arising from the agreement between ICANN and the Sponsorship Agreement is that the Registry ceases to operate as the Registry for a given domain name. The said entity is obliged to cooperate in transferring the administration of the domain name to its successor; in particular, to transfer all the ccTLD data (e.g., the database containing the connotations between IP addresses and domain name addresses).

\subsubsection{Memoranda of Understanding}

The second category of documents under analysis, Memoranda of Understanding, contains the remaining documents made available by ICANN on its website, which are those, pertaining to .ng, .af, .bi, .la, .ps, .mw, .md domain names. The purpose of the Memoranda of Understanding, as specified in their wording, is to formalize each and every time the legal relationship between the parties. The parties assume at the very beginning that such a memorandum is impermanent and transitory in nature, and that it shall remain in force as long as it is the intention of each party, and that it shall be replaced in the future with another, more permanent agreement, which will provide for a potential involvement of Governmental Authorities in the management of a given ccTLD. It, therefore, seems that the Sponsorship Agreement discussed above is to become such a more permanent agreement and that the Memorandum of Understanding constitutes a declaration of intention to enter into such an agreement in the future.

The Memorandum of Understanding is composed of recitals, presenting the information on the parties to the Memorandum, followed by a mutual recognition of the functions performed by the parties, the obligations of ICANN and ccTLD Manager as well as by other provisions. The obligations of ICANN stipulated in the documents under analysis are as follows:

a) Maintenance of a stable, secure and reliable Authoritative-Root database containing the information on ccTLDs operating in the DNS system and the entities administering their registries,

b) Designation of administrative and technical contact persons for reference purposes,

c) Updating of the name server information concerning the links between IP addresses and domain name addresses related to the subdomain names registered under a given ccTLD, 
d) Updating the database for the Registry contact information,

e) Publication of the information on the delegated domain name in the WHOIS database,

f) Taking measures aimed at coordinating the Top Level Domain system to ensure that it is operated in a stable and secure manner,

g) Maintenance of the records related to the delegation of a given ccTLD,

h) Notification of any changes made to ICANN's contact information.

It should be noted that the obligations of ICANN towards the Registry, referred in the Memorandum as the Manager, are identical with the obligations imposed under Sponsorship Agreements discussed above. The section on the obligations of ICANN does not oblige ICANN to recognize the other party as the Registry for a given domain name throughout the term of the agreement, yet it does contain a statement on the recognition of the other party as the Registry throughout the term of the agreement, which implies such an obligation has arisen. By way of analogy to Sponsorship Agreements, the domain name Manager acquires under the discussed Memoranda of Understanding a number of rights, including, in particular, the competence to confer certain rights on the domain name subscribers pursuant to the Internet domain name registration agreement.

The agreements provide for the following obligations of a given ccTLD Manager:

a) Ensuring that name servers for the delegated ccTLD are operated and maintained in a stable and secure manner,

b) Granting ICANN constant access to the so-called zone file as well as to upto-date data on the registration of subdomain names within a delegated domain name (such obligations have not been provided for in the agreement on the .ng domain name),

c) Ensuring the safety and integrity of the Registry database, in particular by the establishment of database backup by a third party,

d) Ensuring the accuracy and completeness of the Registry contact information,

e) Maintaining the website containing detailed information on the entity performing the function of the Registry for ccTLD and on relevant policies, as well as any other data required to register a domain name,

f) Making periodic financial contributions to ICANN to meet its operating expenses,

g) Ensuring compliance with ICANN policy on the interoperability of the delegated ccTLD with other elements of the DNS system and the Internet ${ }^{35}$.

35 The formulation of this obligation corresponds with an analogous obligation included in Sponsorship Agreements, yet it has not been placed in the section of the agreement addressing the obligations of the ccTLD Manager, as was the case with the Sponsorship Agreement. This fact does not affect the legitimacy of viewing this duty as an obligation of the Registry towards ICANN. 
The obligations of the Registry to ICANN specified above overlap, to some extent, with the obligations of the Sponsorship Organization arising from Sponsorship Agreements. It can be inferred from the comparison of the obligations of the Registry stipulated in both types of agreements that the discrepancies between the two categories of documents in the scope under discussion lie in the fact that under Memoranda of Understanding the Registry is additionally obliged to maintain a website containing detailed information on the entity performing the function of the Registry for ccTLD and on the policies in operation in this respect, as well as any other data required for the purpose of registering a domain name. The remaining obligations of the Registry to ICANN are identical in both types of agreements, it should be emphasized, however, that, unlike in Sponsorship Agreements, Memoranda of Understanding do not refer to any attachment which would specify the terms of establishing the amount of the financial contribution. Memoranda of Understanding only stipulate that the contribution amount shall be based upon the price list prepared by ICANN.

Memoranda of Understanding do not provide for the right to use the name or logo of ICANN by the Registry, as is the case with Sponsorship Agreements. Another discrepancy is the exclusion of any (not only financial) liability of the parties for breaching or terminating the agreement, whereas it has been made expressis verbis in the Memorandum of Understanding (section 6.2) that the sole result of breaching the agreement is its termination under section 6.1. Such a provision is void, however, because by virtue of section 6.1 the Memoranda of Understanding can be terminated by either party without cause upon a ninety day notice ${ }^{36}$, and, in urgent situations, upon a thirty day notice; hence, a breach of contractual obligations by one party does not generate unilateral-modification right for the other party, because the said right is already enjoyed since the conclusion of the agreement. Contrary to Sponsorship Agreements, Memoranda of Understanding give little attention to termination, which is governed by section 6.1 .

\subsubsection{The Content of Agreements between ICANN and Other ccTLDs Registries - A Reconstruction Attempt}

As has already been pointed out, the documents discussed above are the only written contracts between ICANN and ccTLD Registries made available by ICANN on its website. It is likely that the delegation of the remaining ccTLDs operating in the cyberspace is not based on written agreements. Such a thesis may be put forward in view of the reasons explained hereinabove with a probability bordering on certainty, in particular with respect to the contractual relationship between ICANN and NASK (Naukowa i Akademicka Sieć Komputerowa) - the Registry for the .pl, and Kaunas Technical University - the Registry for the .lt. Assuming consistently the 
standardization of ICANN activities, corroborated by close similarities exhibited by the agreements with Registries, and, based on the content of these contracts, one could attempt to identify, at least in general terms, the rights and obligations of ICANN and the Registry for ccTLD toward each other when their relationships are based on non-written agreements.

There is no denying the fact that the entity performing the function of the Registry for a given ccTLD is recognized by ICANN as having full capacity in this respect. It is due to either a written statement of such a stance by ICANN (the letters of exchange or the accountability framework correspondence mentioned above), or it can be inferred from the behaviour of ICANN towards the Manager of a given domain name (per facta concludentia). As the Registry for a given domain name, the entity is conferred the right to register and maintain subdomain names within this domain name and to derive benefits therefrom. It seems that also the remaining obligations of ICANN towards the Registry indicated both in Sponsorship Agreements and in Memoranda of Understanding will apply in this respect in light of their identical nature.

The Registry for a given domain name is obliged, in the first place, to make financial contributions to ICANN, yet no information is available on the mechanisms for establishing the amount of the said contribution. As has already been mentioned, such an obligation has been stipulated in each available written agreement and, what is more, the payment of fees to ICANN has been, failing a written agreement, confirmed by the representative of Kaunas University of Technology, which is an argument in favour of a thesis that such an obligation arises, as a rule, for all Registries of ccTLDs $^{37}$. It also seems that the remaining obligations of the Registry towards ICANN stipulated both in Sponsorship Agreements and in Memoranda of Understanding shall be applicable in this case at least to the extent, to which they correspond to one another in all available written agreements.

It should be observed that, in the absence of a written representation of the content of memorandum concluded between ICANN and the Registry for a given domain name, demonstrating the existence of the above mentioned rights or obligations is highly problematic in practice, because it would have to draw on a peculiar analogy to the content of written agreements concluded by ICANN with other entities, and on a thesis of the standardization of the content of legal relationships between ICANN and the Registries for ccTLDs ${ }^{38}$. The content of other agreements could be used for

37 Doubts may surround the existence of such an obligation in respect of .tk (Tokelau) domain name, which, in view of free registration and maintenance of subdomain names with this suffix, is the most popular ccTLD in the world with the number of registered domains exceeding 20 million, source: <https://centr.org/index.php?q=system/files/share/domainwire_stat_ report_2013_3.pdf>. [accessed on 2014-03-03].

38 It seems, however, that this observation should not be linked with the existence on the part of ICANN contractor the right to perform the function of the specific domain Registry on the 
demonstrating the existence of similar rights or obligations under a given contract which had not been concluded in writing, and would thus not so much give rise to these obligations (rights), but serve as an evidence to prove their existence. Another useful mechanism for establishing the existence or the absence of a specific obligation (right) would also be the investigation of (often) many years of contractual practice developed between the entities involved in a given legal relationship as well as any potential statements supplied by the parties in the course of their cooperation (e.g., included in the mentioned above letters of exchange or accountability framework correspondence).

\section{Conclusions}

Prima facie, entering into written agreements on the delegation of Top Level Domains, which govern mutual rights and obligations of the parties to this agreement, seems to be a standard in the entire domain name space. It appears, however, that ccTLDs currently in operation in the virtual space have been delegated without entering into written agreements, although the Registry for ccTLD simultaneously performs the function of DNS system administrator in a given geographic area (or, as a matter of fact, in a given part of cyberspace), which must entail a number of detailed rights and obligations. The absence of any regulations of mutual relations in the form of written agreements comes as an even greater surprise, all the more that performing the function of the Registry is usually a significant undertaking both in terms of $\operatorname{costs}^{39}$ and infrastructure, and sometimes the entities acting in the capacity of Registries are set up solely for the purpose of performing this function.

The findings of the study lead to a conclusion that there are three models for the governance of mutual rights and obligations between ICANN and ccTLD Registries:

1) Non-written agreement model,

2) Temporary written agreement model,

3) Permanent written agreement model.

The prevalent model, as regards ccTLDs, is the model involving non-written agreements, content of which is unspecific and, in the event of a dispute, may give rise to many doubts. The model appears also to be the least permanent from among all the variants. The remaining two models differ from each other in the degree of detail as regards its provisions and in certain secondary obligations and rights of

basis of exclusivity and the consequences arising from this fact, as the entitlement to perform the said function and correlated to it obligation of ICANN to respect this state of affairs is central to the legal relationship created between the said entities.

39 It is worthwhile to recall that in 2003 the maximum amount of the total annual contribution to ICANN under the agreements concluded with Registries of the .ky (Cayman Islands) and .pw (the Republic of Palau) is estimated at five and a half million US dollars, and these domains have a relatively low number of registered subdomains compared with, at least, the .pl ccTLD. 
the parties, but, in the first place, in the permanence of the obligation. In the model involving temporary written agreements, which is based on the so-called Memoranda of Understanding, each party may at any time unilaterally terminate the relationship upon a relatively short notice. In the permanent written agreement model, under which Sponsorship Agreements are being concluded, the Registry may terminate the agreement at any time, upon a longer - six month - notice, whereas ICANN may terminate the obligation relationship only under the circumstances listed in the agreement.

The relationship between ICANN and Registries of .pl and .lt domain names is governed by a non-written agreement model, which should be viewed as a negative thing. It seems that there are no formal obstacles to "formalizing" the relationship between these entities and to reflect the legal relationship between them in the form of a written agreement. Without a doubt, such a solution would stabilize the legal position of NASK and Kaunas University of Technology and, what is more, would contribute to ensuring the transparency of the legal relationship between these entities. It should be remembered that, in light of the assumption that the management of a ccTLD should be effected in the interest of the community of the country (autonomous area, a territory) a given domain pertains to; it is, therefore, desirable for the content of the contractual relationship underlying the administration of a given domain name to be strictly defined, unambiguous and publicly available to the community members. Establishing in detail and describing the content of such an obligation relationship is currently impossible, and an attempt at its reconstruction made in this article as based on the assumptions and the texts of the agreements on the administration of other ccTLDs seems to be a stopgap measure, running a high risk of error.

It should also be pointed out that ICANN is privileged in the relationship with ccTLD Registries due to being a monopolist (in factual terms) on the Top Level Domain market. In light of the above stated, the absence of regulations governing mutual rights and obligations under a written agreement may endanger the interests of the Registries, which are not duly protected. In particular, the absence of specific periods of time and causes for the termination of the legal relationship between these entities may lead to a situation, in which the Registry ceases, all of a sudden, to be recognized by ICANN as the Registry (and, for example, the Registry's function is delegated to another entity), which means that the said Registry is incapable of registering and maintaining subdomain names in the DNS system, which may, in consequence, give rise to a substantial material damage incurred by this entity. It should be remembered that the Registry enters into contractual relationships with the entities registering subdomain names under a given ccTLD, and the ability to perform contractual obligations arising from these agreements (including the obligations which are permanent in nature) depends on whether or not the Registry has the competencies conferred by acting in the capacity of the Registry. In view of the above stated, it is evidently desirable to define the content of the legal relationship 
between the Registry and ICANN as clearly and as precisely as possible in agreements made in writing.

\section{References}

Apke, T. M. Legal Strategies in Resolving Domain Name Disputes. Industrial Management \& Data Systems. 2003, 103/5: 332-228.

Bettinger, T. (ed.). Domain Name Law and Practice. An International Handbook. New York, 2005.

Bettinger, T. (ed.). Handbuch des Domainrechts. Nationalne Schutzsysteme und international Streitbeilegung. Cologne-Munich, 2008.

Dinwoodie, G. B. (National) Trademark Law and the (Non-national) Domain Name System. University of Pennsylvania Journal of International Economic Law. 2000, 21(3): 495-521.

Froomkin, A. M. Wrong Turn in Cyberspace. Using ICANN to Route around the APA and the Constitution. Duke Law Journal. 2000, 50: 17-184.

Jacobs, G. Internet-Specific Collisions of Trademarks in the Domain-Name System - An Economic Analysis Based on U.S. Law. International Review of Intellectual Property and Competition Law. 2006, 2(37): 156-179.

Klein, H. ICANN and Internet Governance: Leveraging Technical Coordination to Realize Global Public Policy. The Information Society. 2002, 18: 193-207.

Komaitis, K. The Current State of Domain Name Regulation. Domain Names as Second-class Citizens in a Mark-dominated World. New York, 2010.
Kulesza, J. International Internet Law. New York, 2012.

Lipton, J. Internet Domain Names, Trademarks and Free Speech. Cheltenham-Northampton, 2010.

Liu, J. P. Legitimacy and Authority in Internet Coordination: A Domain Name Case Study. Indiana Law Journal. 1999, 74: 587-626.

Malisuwan, S.; Xu, J. Conflict of Domain Name and Trademark in Thailand. International Journal of the Computer, the Internet and Management. 2007, 1(15): 63-70.

Mukherjee, S. Passing off in Internet Domain Names - A Legal Analysis. Journal of Intellectual Property Rights. 2004, 9: 136-147.

Parchomovsky, G. On Trademarks, Domain Names, and Internal Auctions. University of Illinois Law Review. 2001, 1: 211-240.

Postel, J. Domain Name System Structure and Delegation. Request for Comments. 1591 [interactive]. [accessed on 2014-03-03]. <http:// www.ietf.org/rfc/rfc1591.txt $>$.

Sauliunas, D. Problems of Legal Nature of Internet Domain Names. Jurisprudencija. 2003, 47(39): 29-37.

Senftleben, M. The Trademark Tower of Babel - Dilution Concepts in International, US, and EC Trademark Law. International Review of Intellectual Property and Competition Law. 2009, 1(40): 45-77. 
Weinberg, J. ICANN and the Problem of Legitimacy. Duke Law Journal. 2000, 50: $187-260$.
Wang, F. F. Domain Names Management and Legal Protection. International Journal of Information Management. 2006, 26: 116-127.

\title{
ICANN IR CCTLDS ADMINISTRATORIŲ TARPUSAVIO TEISIŲ IR PAREIGŲ REGULIAVIMAS REMIANTIS .PL (LENKIJA), .LT (LIETUVA) IR KITŲ DOMENŲ VARDŲ PAVYZDŽIAIS
}

\author{
Mariusz Zelek \\ Poznanès Adomo Mickevičiaus universitetas, Lenkija
}

Anotacija. Straipsnyje analizuojamas klausimas dèl abipusiu teisiu ir pareigų, kylančiu iš susitarimu, sudarytu tarp ICANN ir ccTLDs registrų. Darbe pateikiamas palyginimas turiniu visu prieinamu rašytiniu susitarimu, sudarytu tarp ICANN su registrais, ir šios analizés pagrindu daromos išvados dèl teisinių santykių, susijusių su .pl ir .lt domenu vardu administravimu, turinio.

Reikšminiai žodžiai: domenu vardai, ICANN, ccTLD, domenu vardų sistema (DNS), civiline teisé, teisinio santykio turinys, internetas.

\section{THE GOVERNANCE OF MUTUAL RIGHTS AND OBLIGATIONS OF ICANN AND THE REGISTRIES FOR CCTLDS ON THE EXAMPLE OF THE .PL (POLAND), .LT (LITHUANIA) AND OTHER SELECTED DOMAIN NAMES ${ }^{40}$}

\author{
Mariusz Zelek \\ Adam Mickiewicz University in Poznań, Poland
}

Summary. The Internet Corporation of Assigned Names and Numbers (ICANN) is involved in the cooperation with Top Level Domain Registries, under which the

40 The article was written within the framework of a research project entitled "The Content of the Entitlement of Naukowa i Akademicka Sieć Komputerowa (NASK) to Perform the Function of Registry for the Country Code Top Level Domain for Poland in Light of the Delegation of Subdomains under the Agreement on the Registration of an Internet Domain Name with the .pl Suffix", for the performance of which the author was awarded a research grant by the Dean of the Faculty of Law and Administration at Adam Mickiewicz University in Poznań. 
latter are empowered to manage specific parts of the global system of Internet domain names. The function of Registry for the .pl ccTLD is performed by a research institute the Research and Academic Computer Network, referred to as NASK (Naukowa i Akademicka Sieć Komputerowa) with its registered office in Warsaw. The function of the Registry for the .lt ccTLD is performed by the Kaunas University of Technology.

The contractual relationship between ICANN and these Registries is not based on a written agreement, what makes a precise definition of the scope of competence assigned to the .pl and.lt. Registry is highly problematic in practice, because it would have to draw on a peculiar analogy to the content of written agreements concluded by ICANN with other entities, and on a thesis of the standardization of the content of legal relationships between ICANN and the Registries for ccTLDs. It seems, however, that this observation should not be linked with the existence on the part of ICANN contractor the right to perform the function of the specific domain Registry on the basis of exclusivity and the consequences arising from this fact, as the entitlement to perform the said function and correlated to it obligation of ICANN to respect this state of affairs is central to the legal relationship created between the said entities.

In light of the assumption that the management of a ccTLD should be effected in the interest of the community of the country (autonomous area, a territory) a given domain pertains to, it is desirable for the content of the contractual relationship underlying the administration of pl and .l domain names to be strictly defined, unambiguous and publicly available to the community members. Establishing in detail and describing the content of such an obligation relationship is currently impossible, and an attempt at its reconstruction made in this article as based on the assumptions and the texts of the agreements on the administration of other ccTLDs seems to be a stopgap measure, running a high risk of error.

Keywords: domain names, ICANN, ccTLD, Domain Name System (DNS), civil law, content of legal relationship, Internet.

Mariusz Zelek, Poznanės Adomo Mickevičiaus (Lenkija) Teisės ir administravimo fakulteto Civilinès, komercinès ir draudimo teisès doktorantas, advokatas. Mokslinių tyrimų sritys: interneto ir domenų vardų teisè, intelektinès nuosavybès teisé, civilinè ir komercinè teisè.

Mariusz Zelek, Adam Mickiewicz University in Poznań (Poland), Faculty of Law and Administration, Department of Civil, Commercial and Insurance Law, PhD candidate, Advocate. Research interests: Internet and domain names law, intellectual property law, civil and commercial law. 